\title{
INCIDENCE AND ANATOMIC LOCALIZATION OF ORAL CANDIDIASIS IN PATIENTS WITH AIDS HOSPITALIZED IN A PUBLIC HOSPITAL IN BELO HORIZONTE, MG, BRAZIL
}

\author{
Ilanna G. GABLER ${ }^{1}$, Anne C. BARBOSA ${ }^{2}$, Raquel R. VILELA ${ }^{3}$, Sandra LYON $^{4}$, Carlos A. ROSA $^{5}$
}

\author{
1- DDS, MSc, PhD Student in Microbiology, Department of Microbiology, Institute of Biological Science, Federal University of Minas Gerais, \\ Belo Horizonte, MG, Brazil. \\ 2- Student of Biological Sciences, Department of Microbiology, Institute of Biological Science, Federal University of Minas Gerais, Belo \\ Horizonte, MG, Brazil. \\ 3- DDS, MSc, PhD, Clinical Micology, Newton Paiva University Center, Belo Horizonte, MG, Brazil. \\ 4- DDS, MSc, PhD, Eduardo de Menezes Hospital, Belo Horizonte, MG, Brazil. \\ 5- DDS, MSc, PhD, Associated Professor of Department of Microbiology, Institute of Biological Science, Federal University of Minas Gerais, \\ Belo Horizonte, $M G$, Brazil. \\ Corresponding address: Prof. Dr. Carlos A. Rosa, Department of Microbiology, ICB, C.P. 486, Federal University of Minas Gerais, Belo \\ Horizonte, MG, 31270-901, Brazil. Phone: +55-31-3499-2739. Fax: +55-31-3499-2730. E-mail: carlrosa@icb.ufmg.br
}

Received: November 26, 2007 - Modification: March 1, 2008 - Accepted: March 29, 2008

\begin{abstract}
The type of oral $\mathrm{mm}^{3}$ and hospitalized in a public hospital (Eduardo de Menezes Hospital) in the city of Belo Horizonte, MG, Brazil. Yeasts were isolated using Chromagar ${ }^{\circledR}$ Candida. The results show that $50.7 \%$ of these patients had oral candidiasis. The pseudomembranous form was the most frequent clinical manifestation of oral candidiasis, followed by the erythematous and angular cheilite forms. The most common site of these clinical forms of oral candidiasis was the tongue. Candida albicans was the most common yeast species isolated from the lesions. However, other species were also found to be associated with these forms of oral candidiasis.
\end{abstract}

Key words: Candidiasis, oral. Acquired immunodeficiency syndrome. Opportunistic yeasts. Candida albicans.

\section{INTRODUCTION}

Oral candidiasis is the most common opportunistic infection in patients with AIDS. This disease occurs in between 80 and $90 \%$ of these patients, generally when the CD4 counts are below 200 cells $/ \mathrm{mm}^{3}$. The resultant decrease in systemic and mucosal immune integrity is, in turn, associated with an increased frequency of oral lesions ${ }^{3}$. The degree of immunodeficiency determines the recurrence and severity of this mycotic infection ${ }^{2,3,7,15}$.

There are several clinical manifestations of oral candidiasis, the most common being the pseudomembranous, erythematous, angular cheilitis, hyperplastic and mucocutaneous forms $\mathrm{s}^{5,6,19}$. Diagnosis is made by clinical exam and exfoliative cytology. Treatment involves the use of antifungal therapy, but failures in treatment are observed as a result of the debility of the immune system of AIDS patients and drug resistance of the yeast species ${ }^{6}$.

Several yeast species of the genus Candida have the ability to cause oral candidiasis. The correct identification of the etiological agent can indicate the best therapeutic option for the treatment of these patients. This identification is important because some opportunistic yeast species respond differently to antifungal agents used for treatment ${ }^{1,15}$. C. glabrata and C. krusei are frequently resistant to fluconazole, and a significant proportion of isolates from these species may also have a reduced susceptibility to amphotericin B. In addition, C. lusitaniae may be resistant to amphotericin $\mathrm{B}^{1}$. The objective of this study was to conduct clinical exams in patients with AIDS in order to verify the incidence of oral candidiasis and the clinical forms of these oral lesions. Yeast species associated with the clinical forms of oral candidiasis were also identified.

\section{MATERIALAND METHODS}

The samples were collected from adult patients with AIDS hospitalized in the Eduardo de Menezes Hospital, 
situated in the city of Belo Horizonte, state of Minas Gerais, Brazil. The study included 67 patients, 44 men and 23 women, who signed a written informed consent form. Clinical exams were performed to evaluate the presence of oral candidiasis in these patients and to record the clinical and anatomic localization of the lesions. All individuals examined in this work had CD4 counts bellow 200 cells $/ \mathrm{mm}^{3}$ at the time of exam. All clinical exams were conducted by a single researcher.

Samples were collected from patients with oral candidiasis using a sterile swab. The material was inoculated on Chromagar ${ }^{\circledR}$ Candida (Difco Laboratories, Detroit, MI, USA), and the plates were incubated at $37^{\circ} \mathrm{C}$ for 5 days. The different yeast morphotypes from each sample were isolated, purified, and stored in a freezer at $-86^{\circ} \mathrm{C}$ for later identification. The yeast strains were characterized by standard methods ${ }^{19}$. The following physiological tests were used: fermentation of D-glucose, D-galactose, sucrose, maltose, lactose and raffinose; growth on D-glucose, Dgalactose, L-sorbose, sucrose, maltose, celobiose, trehalose, lactose, melebiose, raffinose, melezitose, inulin, soluble starch, D-xylose, L-arabinose, D-arabinose, D-ribose, Lrhamnose, D-glucosamine, N-acetyl-D-glucosamine, methanol, ethanol, glycerol, erytritol, ribitol, galactitol, Dmannitol, D-glucitol, xylitol, salicin, D-gluconate, DL-lactate, succinate, citrate, inositol, hexadecane, acetone, 2-propanol and ethyl acetate as carbon sources; growth on nitrate, nitrite, L-lysine, ethylamine and cadaverine as nitrogen sources; growth at $30,37,40$ and $42^{\circ} \mathrm{C}$; growth on media with $50 \%$ of glucose and $10 \%$ of $\mathrm{NaCl}$; tolerance to $1 \%$ acetic acid; formation of extracellular amyloid compounds; Diazonium Blue B color reaction, and resistance to $0.01 \%$ and $0.1 \%$ of cycloheximide. Yeasts were identified based on the taxonomic keys of Kurtzman and Fell ${ }^{10}$ (1998).

\section{RESULTS}

Thirty-four individuals (50.7\%), 20 men and 14 women, had oral candidiasis at the time of clinical exam (Table 1). Twenty-four men and 9 women did not have clinical lesions. The clinical forms of candidiasis observed were pseudomembranous, angular cheilitis and erythematous. The pseudomembranous type was found in 23 individuals with candidiasis, occurring in multiple anatomic sites in 6 individuals (Table 1). The pseudomembranous form occurred on the tongue (55.5\% of the lesions), buccal mucosa (37\%), and palate $(7.4 \%)$. Erythematous candidiasis was found in 11 patients (two men and nine women). The tongue was the anatomic location of $52.6 \%$ of the lesions, followed by the palate $(26.3 \%)$ and the remaining oral mucosa (21\%). Angular cheilitis was found in 6 individuals, and all cases appeared

TABLE 1- Oral candidiasis and occurrence of yeasts in lesions of patients with AIDS hospitalized in a public hospital in Belo Horizonte, MG, Brazil

\section{Female patients}

Number of individuals without oral candidiasis

Number of individuals with oral candidiasis

Pseudomembranous candidiasis

C. albicans

C. grabrata

C. tropicalis

C. parapsilosis

C. guilliermondii

Erythematous candidiasis

C. albicans

C. dubliniensis

C. krusei

C. grabrata

C. tropicalis

Angular cheilitis

C. albicans

C. tropicalis

C. grabrata

C. krusei

\section{Male patients}

24

20

18

14

4

2

3

1

2

2 
in patients who already had other clinical lesions. In 2 patients, angular cheilitis was found together with the erythematous form, and in 4 patients, it was found along with pseudomembranous lesions.

Candida albicans was isolated in 16 of 23 patients with pseudomembranous candidiasis, with C. glabrata occurring in 5 patients and C. tropicalis in three patients. Candida parapsilosis was found in association with $C$. albicans in 3 cases of pseudomembranous candidiasis, and $C$. guilliermondii was isolated in one lesion. Candida albicans was also present in 9 out of the 11 cases of erythematous candidiasis. Candida tropicalis was isolated in one patient in whom C. albicans was also found. Other Candida species associated with erythematous candidiasis were $C$. glabrata, C. krusei, and C. dubliniensis, with each species observed in one lesion. Candida albicans was found in all patients with angular cheilitis. In 2 of them, an association with $C$. tropicalis was found. In 1 patient with angular cheilitis, the opportunistic yeast species $C$. albicans, C. glabrata, $C$. krusei, and C. tropicalis were isolated from the same lesion.

\section{DISCUSSION}

Thirty-four individuals with AIDS hospitalized in the Eduardo de Menezes Hospital examined in the present study had oral lesions. Souza, et al. ${ }^{17}$ (2000) reported that candidiasis was the most frequent oral infection in patients with AIDS in the city of Natal, in the state of Rio Grande do Norte, occurring in $79.7 \%$ of men and $80.7 \%$ of women. Ferreira, et al. ${ }^{4}$ (1999) also found similar prevalence of oral candidiasis in patients with AIDS in Salvador, in the state of Bahia. The pseudomembranous, angular cheilitis, and erythematous forms of candidiasis were observed in the patients in our work. These clinical forms of the disease have been reported in studies of oral infections in patients with AIDS in different regions of the world ${ }^{5,11,14,15,17,18}$ and are considered the most common forms of these lesions. The pseudomembranous type was the most common form of oral candidiasis in the patients, occurring in multiple anatomic sites in 6 individuals. The pseudomembranous form has also been reported by Kumarasamy, et al. ${ }^{9}$ (2005) to be associated with the most serious cases of immunodeficiency. According to these authors, this clinical form is observed when CD4 cell counts are between 107 and $198 \mathrm{cells} / \mathrm{mm}^{3}$. These cell counts are similar to those found in the patients included in this study. The pseudomembranous form is common in patients with AIDS and is associated with the high degree of immunodeficiency associated with the disease ${ }^{14,18}$. Regarding the anatomic localization, Gileva, et al. ${ }^{5}$ (2004) observed that pseudomembranous lesions occurred mainly on the oral mucosa, tongue, and corners of the lips, where the lesion is denominated angular cheilitis. In our study, the tongue was significantly more affected than the oral mucosa.

Erythematous candidiasis was found in 11 patients in the present study. Tawio, et al. ${ }^{18}$ (2006) studied the oral manifestation of candidiasis in patients with AIDS in Nigeria and observed that erythematous candidiasis was found exclusively in women, a result similar to that observed in the present study. Angular cheilitis appeared in patients who already had other clinical lesions. These prevalences are similar to those found in other studies of AIDS patients ${ }^{5,11,17,18}$. Mattos, et al. ${ }^{13}$ (2004) reported that erythematous candidiasis seems to be associated with angular cheilitis when the CD4 counts are near 200 cells/ $\mathrm{mm}^{3}$, which is similar to the levels found in the patients of our study.

C. albicans was the yeast species most frequently isolated from the lesions in the patients with candidiasis. This yeast is a common opportunistic infectious agent in individuals with oral diseases ${ }^{2,3}$. Sant'Ana, et al. ${ }^{14}$ (2002) demonstrated that $C$. albicans was present in nearly $95 \%$ of patients in the treatment centers for AIDS studied in Brazil. In the present investigation, other opportunistic Candida species were also isolated from the patients' oral lesions. Candida glabrata, C. tropicalis, C. parapsilosis, $C$. guillermondii, C. krusei and C. dublinienisis are frequently isolated from oral lesions of immunocompromised individuals. Kirkpatrick, et al. ${ }^{8}$ (1998) related the presence of C. dubliniensis associated with candidiasis in $73 \%$ of the patients with AIDS in North America. In our study, this species was found in only 1 patient with erythematous candidiasis. C. krusei was isolated from oral candidiasis lesions by Mariano, et al. ${ }^{12}$ (2003) in patients with AIDS in São Paulo, Brazil. In the present work, this species was found in 2 patients, one with erythematous candidiasis and another with angular cheilitis. Some of these non-albicans species were also found associated with $C$. albicans in the same oral lesion in our study. This result suggests that more than one species could be responsible for the oral lesions in these patients. The occurrence of different species of opportunistic yeast species in oral lesions of immunocompromised patients is important for the treatment and management of these infections. The choice for an appropriate antifungal agent should take into account a number of factors, including previous exposure to antifungal agents and the correct species identification ${ }^{1}$. Some opportunistic species may have a reduced susceptibility to determined antifungal agents. C. glabrata and C. krusei are frequently resistant to fluconazole ${ }^{1}$. These species can cause persistent infections in patients with advanced immunosuppression. Therefore, the correct identification of the yeast species associated with oral lesions in AIDS patients is very important for the correct treatment of these individuals.

\section{CONCLUSIONS}

About $50 \%$ of the patients examined in the present study had oral candidiasis, and more men were affected than women. The pseudomembranous form was the most common clinical manifestation of the disease, and C. albicans was the etiological agent most frequently isolated from the lesions. Other Candida species were also isolated from the 
lesions, and in some patients, more than one species was present in the oral lesions.

\section{ACKNOWLEDGEMENTS}

The authors ackowleged finantial support from the Nacional Council for Scientific and Technological Research (CNPq) and the Minas Gerais State Research Foundation (FAPEMIG).

\section{REFERENCES}

1- Antachoupoulos C, Walsch TJ, Roilides E. Fungal infections in primary immunodeficiencies. Eur J Pediatr. 2007;166:1099-117.

2- Bravo IM, Correnti M, Escalona L, Perrone M, Brito A, Tovar V, et al. Prevalence of oral lesions in HIV patients related to CD4 cell count and viral load in Venezuelan population. Med Oral Patol Oral Cir Bucal. 2006;11:E33-9.

3- Coogan MM, Greenspan J, Challacombe SJ. Oral lesions in infection with human immunodeficiency virus. Bull World Health Organ. $2005 ; 83: 700-6$

4- Ferreira RI, Valença AAP Neto, Vianna DC, Sarmento VA, Falcão AFP, Raquim OM. Study of the oral alterations prevalence in patients with HIV at the Hospital University Prof. Edgard Santos - Salvador, Bahia. Rev Fac Odontol Univ Fed Bahia.1999;18:22-7.

5- Gileva OS, Sazhina MV, Gileva ES, Efimov AV, Scully C. Spectrum of oral manifestations of HIV/AIDS in the Perm region (Russia) and identification of self-induced ulceronecrotic lingual lesions. Med Oral. 2004;9:212-5.

6- Gonsalvez WC, Chi AC, Neville BW. Common oral lesions: Part I. Superficial mucosal lesions. Am Fam Physician. 2007;75:501-7.

7- Hung CC, Yang YL, Lauderdale TL, Mcdonald LC, Hsiao CF, Cheng $\mathrm{HH}$, et al. Colonization of human immunodeficiency virusinfected outpatients in Taiwan with Candida species. J Clin Microbiol. 2005;43:1600-3.

8- Kirkpatrick WR, Revankar SG, Mcatee RK, Lopez-Ribot JL, Fothergill AW, McCarthy DI, et al. Detection of Candida dubliniensis in oropharyngeal samples from human immunodeficiency virusinfected patients in North America by primary CHROMagar Candida screening and susceptibility testing of isolates. J Clin Microbiol. 1998;36:3007-12.

9- Kumarasamy N, Vallabhaneni S, Flanigan TP, Mayer KH, Solomon S. Clinical profile of HIV in India. J Med Res. 2005;121:377-94.

10- Kurtzman CP, Fell JW. The yeast: a taxonomic study. Amsterdam: Elsevier Science Publishers; 1998.

11- Liu X, Liu H, Guo Z, Luan W. Association of asymptomatic oral candidal carriage, oral candidiasis and CD4+ lymphocyte count in HIV-positive patients in China. Oral Dis. 2006;12:41-4.

12- Mariano PL, Milan EP, Matta DA, Colombo AL. Candida dubliniensis identification in Brazilian yeast stock collection. Mem Inst Oswaldo Cruz. 2003;98:533-8.

13- Mattos SL, Santos VR, Ferreira EF. Prevalence of oral mucosal lesions in HIV-infected patients at the specialized reference center for infectious and parasitic diseases (Belém-Pará-Brazil). Rev Bras Patol Oral. 2004;3:1-15.
14- Sant'Ana PL, Milan EP, Martinez R, Queiroz-Telles F, Ferreira MS, Alcântara AP, et al. Multicenter brazilian study of oral Candida species isolated from AIDS patients. Mem Inst Oswaldo Cruz. 2002;97:253-7.

15- Sánchez-Vargas LO, Ortiz-Lopes NG, Villar M, Moragues MD, Aguirre JM, Cashat-Cruz M, et al. Point prevalence, microbiology and antifungal susceptibility patterns of oral Candida isolates colonizing or infecting Mexican HIV/AIDS patients and healthy persons. Rev Iberoam Micol. 2005;22:83-92.

16- Sharma G, Pai KM, Suhas S, Ramapuram JT, Doshi D, Anup N. Oral manifestations in HIV/AIDS infected patients from India. Oral Dis. 2006;12:537-42.

17- Souza LB, Pinto LP, Medeiros AMC, Araújo J, Raimundo F, Mesquita OJ. Oral manifestations in HIV infected patients in a Brazilian population. Pesqui Odontol Bras. 2000;14:79-85.

18- Taiwo OO, Okeke EN, Jalo PH, Danfillo IS. Oral manifestation of HIV/AIDS in Plateau state indigenes, Nigeria. West Afr J Med. 2006;25:32-7.

19- Yarrow D. Methods for the isolation, maintenance and identification of yeasts. In: Kurztman CP, Fell JW, editors. The yeasts, a taxonomic study. Amsterdam: Elsevier Science Publishers; 1998. p. 77-100. 